\title{
A Poster Digital Sain Media for Humanity Interaction based Interactive Augmented Reality
}

\author{
Muhammad Ashar*, Azhar Ahmad Smaragdina, Muhammad Iqbal Akbar, \\ Dicki Dwi Prasetya
}

Department of Electrical Engineering, State University of Malang

Malang, Indonesia

*E-mail: muhammad.ashar.ft@um.ac.id

\begin{abstract}
Interactive and innovative learning media supported by Augmented Reality (AR) is specifically used in the field of science in helping the development of student learning process at State University of Malang (UM). This media is designed to build the pillar of learning innovation strategy through IT fusion on curriculum and learning. Specifically, the main target in the development of teaching media with interaction through AR mobile media and science posters integrated with virtual communications is to improve the visual capabilities of information. Several stages to be done to realize this service are: 1) build a framework of the system in a comprehensive manner, 2) testing with a number of students as a user response, 3) making showcase and 4) demonstrating application system with multimedia content with science materials with 3D perspective (animation and interactive video). The software engineering method used in this application development is the waterfall model, while the qualitative method approach is needed to measure the effectiveness and efficacy of this AR science product on increasing the level of student understanding after using this media through a questioner. It is expected that with the development of this media will accelerate the formation of learning innovation in life-based learning in UM in the future. In broader impact, this work will be able to make UM as a learning innovation university as the competitive and superior university as well as become a reference in the technology of learning media.
\end{abstract}

Keywords: augmented reality; learning innovation; science materials.

\section{Introduction}

Face-to-face learning with conventional methods allows learning occurred interactively using various approaches, strategies, and learning methods, while online methods can provide material 
online without limitation of space and time, in addition, learners can more obtain and process information from various sources so, this can support the learning process. Therefore, the development of learning media supported by Augmented Reality that synergizes with multiple resources in the form of a poster of science which is packed in interactive multimedia material and interactive teaching communication between students (learners) and lecturers (expert tutor).

Science poster (Kung Hun, 2013) provides simple science information as a scientific model. This Science Poster is simple because just one sheet, but still, need a more detailed explanation by the author poster or people who are experts in the field of science. Currently, the development of AR poster applications (poster with blended Augmented Reality) (Greig, 2014) is a technological trend to help visualize virtual posters, thereby enhancing the reader's cognitive abilities quickly through multimedia such as animation or video. With the integration of learning innovation between science posters and AR used as blended learning in UM campus, the complete and efficient learning process for learning in the classroom (face-to-face) and outside the classroom using UM poster (integrated science posters with AR and virtual expert communication) can be achieved. There are 5 reasons why it is important to use AR technology, in the field of education with media integration (Wu, 2013): 1) Interactive learning, students can understand better the concept of teaching materials. So one of the fun ways to learn by looking at the visual AR model, 2) Portability and low cost, the provision of learning materials. AR models do not require much funding for the development of teaching materials physically, for example, prototypes and physical models can be illustrated with multimedia animation, 3) Flexible and easy to learn, anyone can access teaching materials anytime and anywhere, in addition, students can also interact with teaching materials available with virtual reality, 4) Lifecycle completed learning, by creating a complete learning cycle with learning experience on AR model that makes it easy for lifelong learning, easy to remember in the long term, and integrated with other access media such as website, etc, and 5) Improving analytic thinking, stimulating the thought of new ideas with interesting learning about the knowledge around us with AR in the digital age.

The focus of this study is how to improve students' thinking comprehension naturally with the ability (level) of varied intelligence in each student that can be increased significantly. With the use of innovative media learning through IT fusion is also conducted testing expert tutor involvement for students who need explanation and frequently asked questions online, then testing techniques with comparative methods between AR poster media and virtual expert tutor is the part of this research. They are important enough to do mapping the level of understanding of students on each teaching material so that the results of research can be a reference development of appropriate curriculum for the institution and also can be a model of innovative learning with newness in the method, as well as research results published on the international journal. 
The target of this research is to realize learning innovation as IT fusion through making learning resource with science poster which can be implemented as extended blended learning in UM campus environment in a number of students and lecturers with science poster service for basic knowledge, practical skills, expert skills and developed skills to support model of life based learning in UM Institutions and other campuses in Indonesia.

\section{Related Work}

Media implementation with Augmented Reality for education is used in assisting self-learning. Various functions are developed in order to improve the quality of learning to accelerate the process of understanding the material. Because AR provides visualization on AR model, focus on content creation project (multimedia content) with a multimodal way like animation, sound, and text in real. The use of AR in education is still in its infancy. Research has found that the most important factor to influence the learning process while working with AR is the presentation of learning content with 3D perspectives. Wu et al (2013) refer to three groups of stakeholders in the development of AR used for education: teachers (lecturers), researchers, and ICT-designers. This is why there is a need for guidance for lecturers and students in the practice of science and teaching and learning process (Lopez, 2013).

One application of AR science is developed by Lopez (2013) by involving the teacher's role in choosing the right and accurate ingredients to describe the digestive and circulatory system by adding expert and experience strategies through video from the organ in real terms.

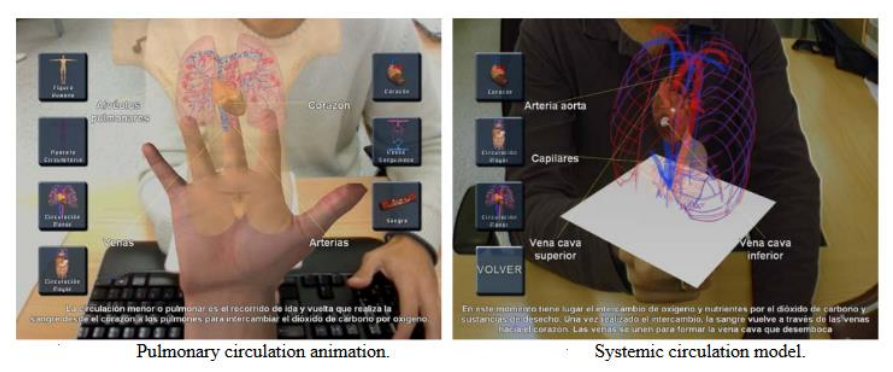

Figure 1. An Augmented Reality Example for Science Materials 


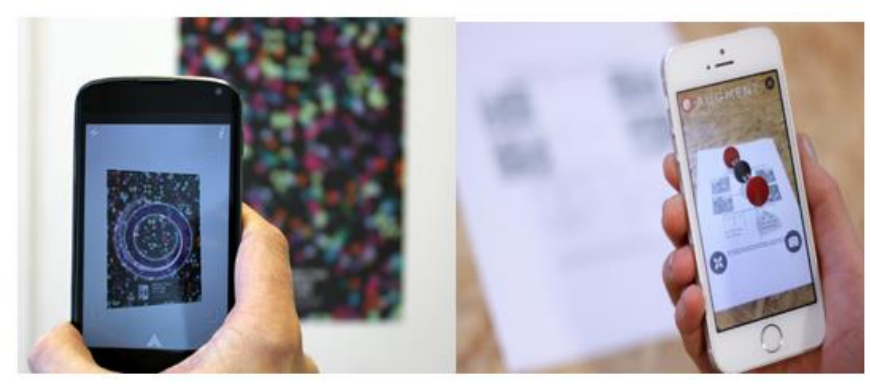

Figure 2. Aurasma: Augmented Reality Poster

(http://news.diginate.com/we-made-an-augmented-reality-poster/)

Learning technology is growing very rapidly today through new advancements and discoveries with the latest technology. At the same time, the use of Augmented Reality in science posters is more promising with the latest exciting facilities of mobile-based multimedia applications such as those developed by the 'Aurasma' (2013) app, available on iOS Apple (iTunes store) and Android (Google Play). Opportunities given by this new innovation offer many features in data presentation.

In the end, the research that will be developed has newness in learning service aspect as a whole (comprehensive) in order to improve student achievement with learning interaction between AR poster media, students, and expert tutor. Development of AR poster media can be seen in the framework (Figure-3) below:

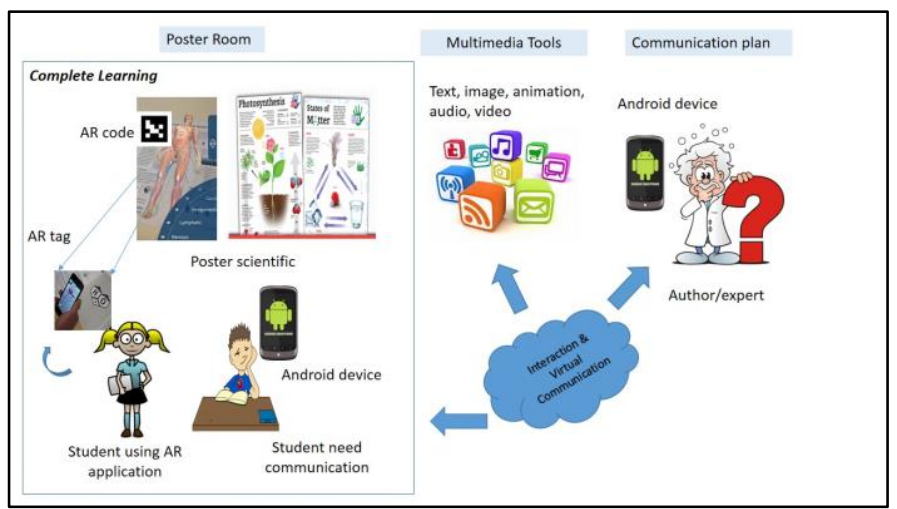

Figure 3. The Framework of UM-Poster Project

Furthermore, the development of this media can be described specifically from the concept of the newness of learning media technology and service system mechanism to be implemented on UM Malang campus to help the achievement of life-based learning (Figure-4). This mechanism demonstrates the implementation process of UM-poster in an effort to develop innovative learning through the mapping of student's potential development to science knowledge with the help of expert tutor available on mobile apps service feature and AR poster. 


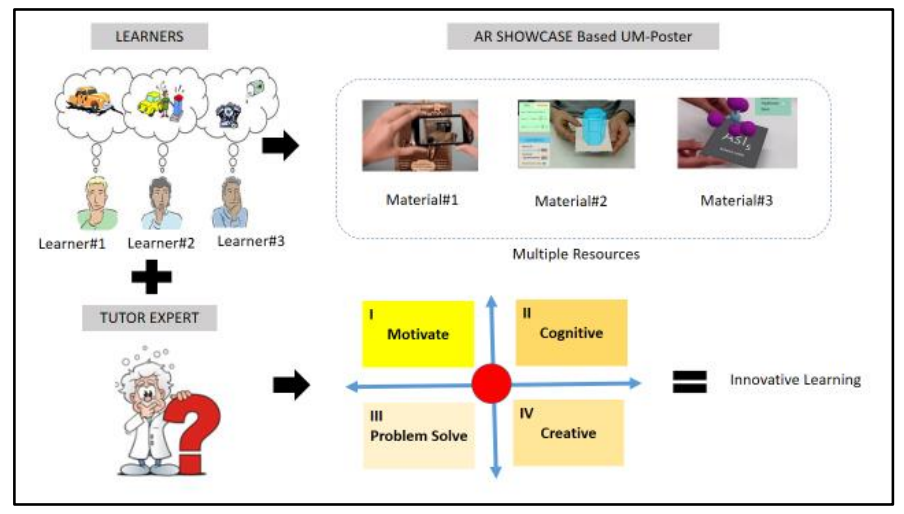

Figure 4. UM-poster mechanism and its implementation as innovative learning.

\section{Research Methodology}

The manuscript should begin with title, abstract, and keyword(s) followed by the main text. The main text should consist of at least IMRaD structure, except for the review article: Introduction, Method/Material, Result and Discussion, and Conclusion; followed by acknowledgement and References.

\section{A. Software Engineering Approach (UM-Poster)}

This research was using Waterfall model (Figure 3) as a software engineering approach methodology. This model provided 5 main steps, namely Analyze requirements, Design, Implement, Test and Operate.

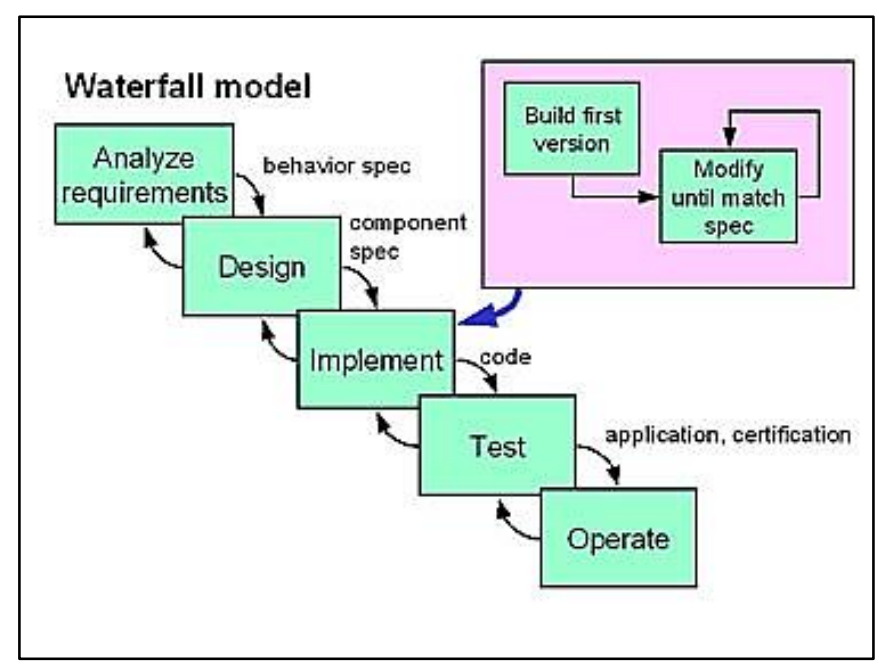

Figure 5. Waterfall model pada layanan sistem interaksi poster sains (UMposter) berbasis Augmented Reality

\section{1) Analyze Requirements}

This stage begins with field observation and literature review by observing, studying and asking students (Diploma and Undergraduate Students) directly or through quisionaire about the use of 
AR technology for learning at the University. The next step is literature review to enhace resources about latest AR technology form the library, online book, article, proceedings and international journals. The last step at this stage is to share knowledge of some literature on innovative learning from various sources of research and international publications.

2) Designing the Prototype

After analyzing the system requirements, both hardware and software, the next step is designing the system prototype. Several phases that need to be done at this stage is determining the type of science posters, design layouts, features and multimedia tools, as well as the design of virtual communications. In addition, it is necessary to specify the type of smartphone devices, application design, information systems, databases, content storage, data query system, and wifi or internet service.

3) Implement

At this stage, researcher implement the prototype design that has developed in the previous step to Android application.

4) Testing

These stages include testing content availability, multimedia tools reliability (audio, video, animation), and virtual communication access (social media) which is judged in terms of access speed and network availability.

5) Operational products and services

At this phase an overall evaluation system is done by measuring the length of time of the participants when use this medium and analyze their understanding of science poster material by asked them to answer several questions. Next, we organize the product demos for various users to assess the performance of the media services and then, maintenance the feedback and changes to the next version of the product and operational development process in the future.

\section{B. Research Methodology}

Qualitative approach are used to identify and analyze the assessment's results from participants (undergraduate students) and experts (lecturer, senior researcher, and educational expert).

The first questionaire provides opened question about ideas and challenges related to the use of Augmented Reality in science education. The second questionaire is designed as closed questions which the participants are asked to assess the importance of several dimensions that need to be identified in science.

Initial prototype is developed based on the first questionaire and enhanced by the results of the second questionaire. The completed prototype is analyzed by research team on a cycled process to ensure that the prototype is well developed. 


\section{Result}

\section{A. Product Description}

In this section we will describe the learning system and science digital content using augmented reality. At a glance, this section provides detail information about the software, design interface, and several features of the augmented reality application.

\section{1) Software description}

Several softwares that used to develop the science digital content combined with augmented reality are:

a. Microsoft Windows 7 Ultimate or above, as the operating system.

b. Unity $3 \mathrm{D}$, is used to create the augmented reality application that will be used in mobile devices (android).

c. Blender 3D, as the application to carve and render the 3D object and develop 3D animation that will be integrated with the AR application.

d. Adobe Photoshop CS 5, as the application to edit images processor and photos.

e. Corel Draw, is used to edit, render an create vector images.

The minimum requirement for the hardware and software to operate the digital science materials integrated with augmented reality are:

a. Mobil devices with android operating system version 4.4 (Kitkat) or above.

b. 4 GB internal memory

c. The rear camera of the smartphone has to be 8 Megapixel in minimum.

d. $1 \mathrm{~GB}$ of RAM

e. Augmented reality application.

\section{2) Interface design}

The framework's design of the learning system that can be seen in Figure 3, where students can learn from poster that has been integrated with augmented reality application. The poster we used in this research is well designed to ensure that the content of the poster is easy to understand and can be integrated with augmented reality application.

Generally, how the augmented reality poster works are divided into several stages:

a. The poster are equipped with marker that used to trigger the AR application.

b. AR application activates the rear camera of the smartphone to scan the poster 
c. When AR application detects the marker in the poster, it will show 3D animation to support the science materials in the poster.

d. Students can interact with the 3D animation, to enhance their learning experience.

The science material which is developed in this research is about the solar system. The design of the poster can be seen in Figure 7. Furthermore, Figrure 6 and 8 depicts the AR application that plays the 3D animation of solar system after detects the marker in the poster.

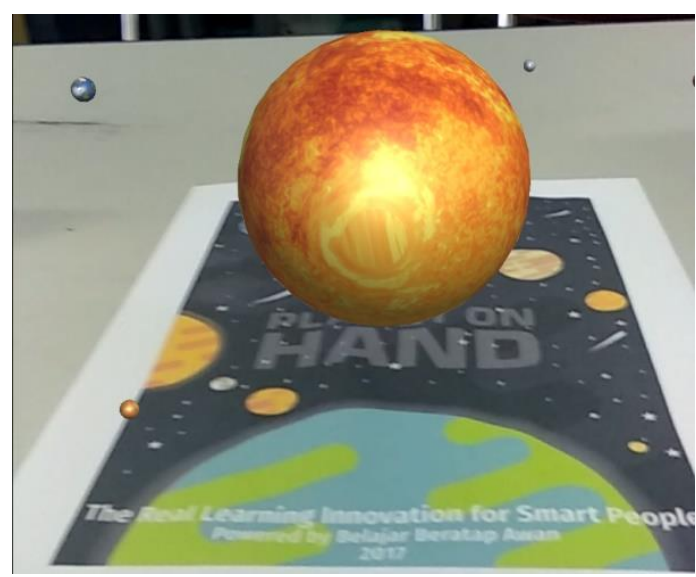

Figure 6. The AR application are captured when scanned the marker in the poster.

\section{B. Data Analysis}

This section will present the test results that consist of 1) the assessment from learning media experts, 2) science material experts, and 3) students.

1) The results of Assessment from Learning Media Experts

Based on Table 1, at a glance, the digital science content integrated with augmented reality has an excellent quality, as the average of all assessment variables is $96.1 \%$. Moreover, the majority of the variables has perfect percentage (100\%). Therefore, we can conclude that this application is well developed and very feasible to be used for learning media. 


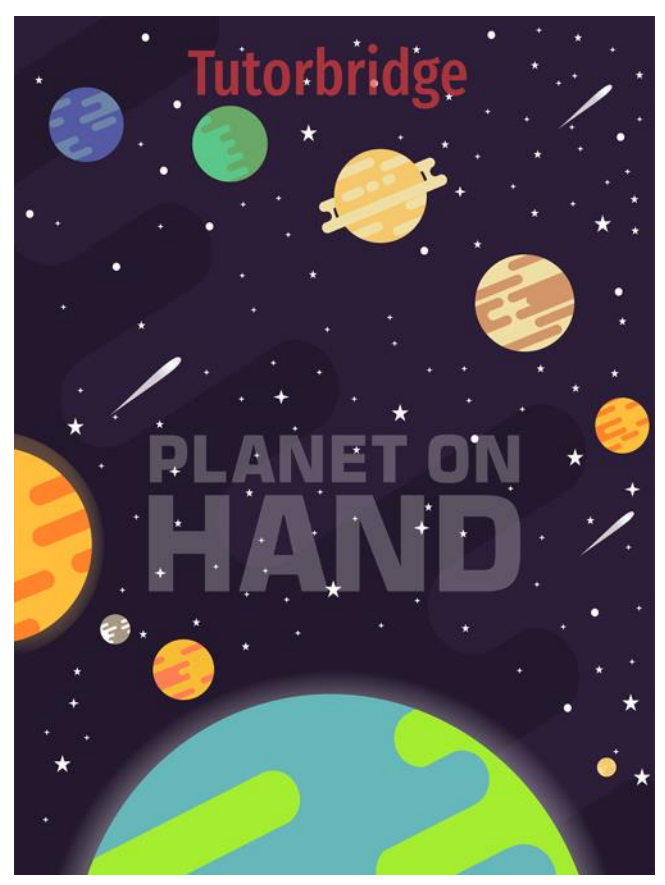

Figure 7. The design of the AR poster

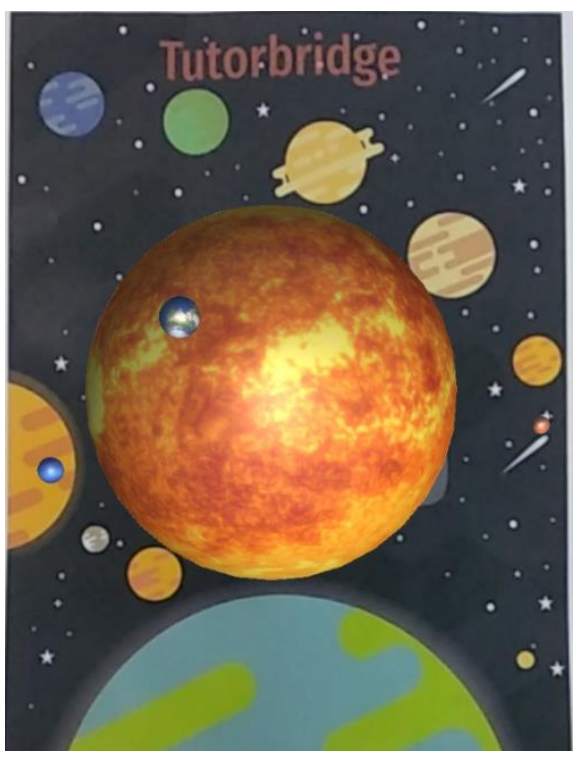

Figure 8. 3D animation played when the AR application detects the marker in the poster.

\section{Tabel 1.}

Data of Expert Media Validation

\begin{tabular}{|c|c|c|c|c|c|c|c|}
\hline \multirow[b]{2}{*}{ No } & \multirow[b]{2}{*}{ Aspects of Assessment } & \multicolumn{2}{|c|}{$\mathbf{X}$} & \multirow[b]{2}{*}{$\sum \mathbf{x}$} & \multirow[b]{2}{*}{$\sum \mathbf{x}_{\mathbf{i}}$} & \multirow[b]{2}{*}{$\%$} & \multirow[b]{2}{*}{ Status } \\
\hline & & & 2 & & & & \\
\hline 1. & Menu yang tersedia sudah berfungsi dengan baik & 4 & 4 & 8 & 8 & 100 & Valid \\
\hline 2. & The availability of manual book & 4 & 3 & 7 & 8 & 87,5 & Valid \\
\hline
\end{tabular}


3. The existence of interaction between users with the system

$\begin{array}{llllll}4 & 4 & 8 & 8 & 100 & \text { Valid }\end{array}$

4. Compatibility with learning activity

$\begin{array}{llllll}4 & 4 & 8 & 8 & 100 & \text { Valid }\end{array}$

5. Overall, the application is developed properly

$\begin{array}{llllll}4 & 4 & 8 & 8 & 100 & \text { Valid }\end{array}$

6. The application is user friendly and easy to use

$\begin{array}{llllll}4 & 4 & 8 & 8 & 100 & \text { Valid }\end{array}$

7. Performance and respon time.

$\begin{array}{llllll}4 & 4 & 8 & 8 & 100 & \text { Valid }\end{array}$

8. The attractiveness of the user interface design

$\begin{array}{llllll}4 & 4 & 8 & 8 & 100 & \text { Valid }\end{array}$

9. The navigation menus/buttons are very helpful

$\begin{array}{llllll}4 & 4 & 8 & 8 & 100 & \text { Valid }\end{array}$

10. The quality of image in the learning materials

$\begin{array}{llllll}4 & 3 & 7 & 8 & 87,5 & \text { Valid }\end{array}$

11. The interface in the media can stimulate the learner to iteract with the totur

$\begin{array}{llllll}3 & 4 & 7 & 8 & 87,5 & \text { Valid }\end{array}$

12. All interfaces are appropriate with learning activities $\quad \begin{array}{lllllll}3 & 4 & 7 & 8 & 87,5 & \text { Valid }\end{array}$

13. 3D animations used in the media are suitable and help the learner to understand the content

$\begin{array}{llllll}4 & 4 & 8 & 8 & 100 & \text { Valid }\end{array}$

$100 \quad 104 \quad 96,1 \quad$ Valid

2) Science Material Experts Validation Data

As we can see from Table 2, this research uses 9 variables to ensure that the AR application is well developed and meet the requirement as an effective learning materials. Based on the data in details, all aspects that assessed by the experts have an outstanding percentage, where the average of all aspects is $97, \%$, slightly higher than the average of learning media experts validation data. It means that the materials in the poster and $3 \mathrm{D}$ animation presented by the AR application are appropriate to be used in learning activity.

\section{3) User Test Result Data}

The last test conducted by the researchers is a user test. The ultimate purpose of this test is to find out whether the augmented reality-based science content that has been developed has met the needs of users, both in terms of attractiveness, ease and conformity with learning materials.

A detailed description of user test results can be seen in Table 3. Based on the data in details, there are three variable namely (1) compatibility and attractiveness illustrations, (2) the suitability and attractiveness of the use of 3D animation, and (3) The use of this learning media can increase the motivation in learning, that have the highest percentage at $95 \%$, while the percentage of other variables are slighlty lower at $90 \%$. Furthermore, the average percentage of all variables is $92 \%$, 
it means that the media that has been developed has the appropriate quality to be used in the learning activities.

Tabel 2.

Data of Expert Content Validation

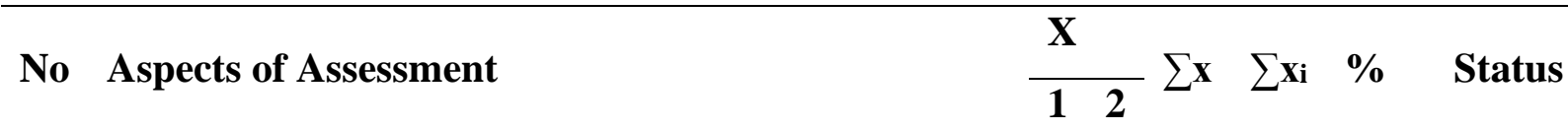

1. The suitability of learning media with the achievement of learning objectives

$\begin{array}{llllll}4 & 4 & 8 & 8 & 100 & \text { Valid }\end{array}$

2. The interface in the media can stimulate the learner to iteract with the totur

$\begin{array}{llllll}3 & 4 & 7 & 8 & 87,5 & \text { Valid }\end{array}$

3. The level of easiness of operation of instructional media

$\begin{array}{llllll}4 & 4 & 8 & 8 & 100 & \text { Valid }\end{array}$

4. The suitability and attractiveness of $3 \mathrm{D}$ animation with learning objectives

$\begin{array}{llllll}4 & 4 & 8 & 8 & 100 & \text { Valid }\end{array}$

5. Conformity and attractiveness of poster design with learning material

$\begin{array}{llllll}4 & 4 & 8 & 8 & 100 & \text { Valid }\end{array}$

6. The learning media can be used to study independently $\begin{array}{llllllll}4 & 4 & 8 & 8 & 100 & \text { Valid }\end{array}$

7. The level of effectiveness of learning media if used as an alternative media in learning activities

$\begin{array}{llllll}4 & 4 & 8 & 8 & 100 & \text { Valid }\end{array}$

8. The clarity of content of learning materials with curriculum

$\begin{array}{llllll}4 & 3 & 7 & 8 & 87,5 & \text { Valid }\end{array}$

9. Students can understand the material easily

$\begin{array}{llllll}4 & 4 & 8 & 8 & 100 & \text { Valid }\end{array}$

SUM

$\begin{array}{llll}70 & 72 & 97,2 & \text { Valid }\end{array}$

Table 3.

User Test Result Data

No Aspects of Assessment

$\begin{array}{lllllllll}\mathbf{X} & & & & & & \\ 1 & 2 & 3 & 4 & 5 & \sum \mathbf{x}_{\mathbf{i}} & \%\end{array}$

\begin{tabular}{llllllllll}
\hline 1 & Interest in learning using this learning media & 4 & 3 & 4 & 3 & 4 & 18 & 20 & 90
\end{tabular}

2

Compatibility and attractiveness Illustrations or drawings on $\quad \begin{array}{llllllll}4 & 3 & 4 & 4 & 4 & 19 & 20 & 95\end{array}$

learning media

3

$\begin{array}{llllllll}\text { The suitability and attractiveness of the use of animation on } & 4 & 4 & 3 & 4 & 4 & 19 & 20\end{array}$

95 learning media

4 Conformity and attractiveness of display design 
The use of this learning media can increase the motivation in $\begin{array}{llllllllll}4 & 4 & 3 & 4 & 4 & 19 & 20 & 95\end{array}$ learning

6 The easiness when operating this media

$\begin{array}{llllllll}4 & 3 & 3 & 4 & 4 & 18 & 20 & 90\end{array}$

$7 \quad$ Material is easy to understand

$\begin{array}{llllllll}4 & 3 & 4 & 3 & 4 & 18 & 20 & 90\end{array}$

SUM

$129 \quad 140$

92

Table 4.

Eligibility Criteria (Sudjana, 1992)

\begin{tabular}{llll}
\hline Categories & Percentage & Qualification & Information \\
\hline 4 & $80 \%-100 \%$ & Valid & No revision \\
3 & $60 \%-79 \%$ & Valid Enough & No revision \\
2 & $50 \%-59 \%$ & Less valid & Need to be revised \\
1 & $0 \%-49 \%$ & Not valid & Need to be replaced \\
\hline
\end{tabular}


Based on the data in Table 1,2, and 3, the average of validity of the learning media in all aspects has reached the appropriate percentage at $95.1 \%$. As this high percentage average is compared with the eligibility criteria in Table 4, augmented reality-based digital science content has "valid" predicat and no need to be revised.

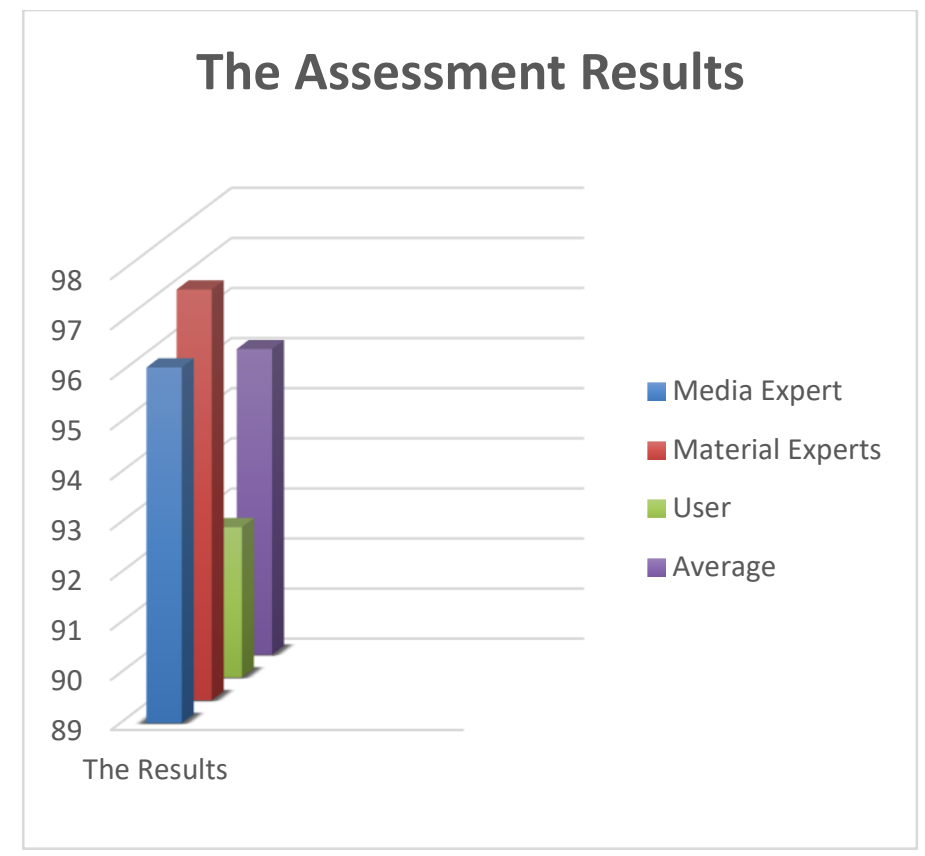

Figure 9. Graph of Trial Results (Media Expert, Materials Expert, and User)

\section{Conclusion}

Based on the process of development and analysis of data test results that have been done by researchers, it can be concluded that:

a. Digital content science based augmented reality has met the criteria as an effective and efficient learning media with the average percentage validity of media experts of $96.1 \%$.

b. The material that has been developed on the digital contents of science based augmented reality has met the material standard with the average percentage validity of material experts of $97.2 \%$.

c. Overall augmented reality-based digital science content that has been developed, can be said to have met the needs of users with a mean percentage of user trials of $92 \%$.

d. The augmented reality-based digital science content has been feasible to use and has been decent to implement in learning activities with an average percentage of all assessment at $95.1 \%$. 


\section{References}

[1] Aurasma. 2013. (online). http://www.aurasma.com.

[2] Bakar, A. N. Zulkifli and N. F. F. Mohamed, "The use of multimedia, Augmented Reality (AR) and Virtual Environment (VE) in enhancing children's understanding of road safety," 2011 IEEE Conference on Open Systems, Langkawi, 2011, pp. 149-154.

[3] Greig P, Higham H. 0102 Using Augmented Reality In Scientific Posters. BMJ Simulation and Technology Enhanced Learning. 2014;1: A74.

[4] Harald Brandt, Marianne Georgsen, Birgitte Lund Nielsen, Håkon Swense, "Augmented Reality for Science Education”, Nordic Studies in Science Education. 2016, volume 12 No 2.

[5] Ibáñez, M., Delgado, C., Leony, D., García, J. J., \& Maroto, D. 2011. "Learning a Foreign Language in a Mixed-Reality Environment”, IEEE internet computing, 15(6), 44-47. IEEE Computer Society.

[6] Kun-Hung Chen. "Affordances of Augmented Reality in Science Learning: Suggestions for Future Research”, Journal of science education and technology, 2013, Volume 22, Issue 4, pp 449-462, Springer.

[7] Krajcik, JS \& Mun, K. 2014. Promises and challenges of using learning technologies to promote student learning of science, in Handbook of Research on Science Education. vol. 2, Taylor and Francis, pp. 337-360. DOI: 10.4324/9780203097267

[8] López Perez, Manuel Contero, “Augmented reality application: a case study on its impact on Knowledge acquisition and retention", The Turkish Online Journal of Educational Technology. 2013, volume 12 issue 4.

[9] Lin, H.C.K., Hsieh, M.C., Wang, C.H., Sie, Z.Y. \& Chang, S.H. 2011. "Establishment and Usability Evaluation of an Interactive AR Learning System on Conservation of Fish". Turkish Online Journal of Educational Technology. 10 (4), pp. 181-187.

[10] Wu, H., Lee, S.W., Chang, H. \& Liang, J.: Current status, opportunities and challenges of augmented reality in education. Computers \& Education, 2013, 62, 41-49.

[11] Stansfield, M., Hainey, T. \& Connolly. "An alternate reality game for language learning: ARGuing for multilingual motivation”, Computers \& Education, 2011, Volume 57, Issue 1, Elsevier. 